\title{
Separation of acid-soluble constituents of soil humic acids by dissolution in alkaline urea solution and precipitation with acid
}

Masakazu Aoyama

\begin{abstract}
Background: Humic substances are considered to be composed of relatively small, heterogeneous molecules bound by weak linkages. The dissociation of acid-soluble constituents from soil humic acids (HAs) during the preparative polyacrylamide gel electrophoresis in the presence of concentrated urea has been previously demonstrated. Moreover, the dissociation of acid-soluble constituents has been attributed to the action of concentrated urea. The aim of this study was to investigate the effects of concentrated urea on the dissociation of acid-soluble constituents of soil HAs.

Results: Three types of soil HAs were solubilized in $0.1 \mathrm{M} \mathrm{NaOH}$ containing $7 \mathrm{M}$ urea and precipitated after $16 \mathrm{~h}$ by acidifying the samples to $\mathrm{pH}$ 1.0. The acid-soluble constituents were separated from the dark-colored precipitates by concentrated urea treatment and accounted for 16-45 \% of the total organic carbon in HAs. Approximately half of the acid-soluble constituents was recovered in the DAX-8-adsorbed fraction. The humification degree of the DAX-8-adsorbed fraction was considerably lower than that of the corresponding unfractionated HA. In contrast, the humification degree of the precipitated fraction increased due to the separation of acid-soluble constituents. The molecular sizes of the DAX-8-adsorbed and DAX-8-non-adsorbed fractions, estimated by high-performance size exclusion chromatography, were similar and smaller than the precipitated fraction. Three-dimensional excitationemission matrix fluorescence spectroscopy revealed that the acid-soluble constituents exhibited fluorescence similar to that of fulvic acid (FA), added to which the DAX-8-non-adsorbed fraction exhibited protein-like fluorescence. Diffuse reflectance infrared Fourier transform spectroscopy showed that the DAX-8-adsorbed fraction contained proteinous moieties and the DAX-8-non-adsorbed fraction was rich in proteinous and polysaccharide moieties.

Conclusions: The present findings suggest that soil HAs are formed by the molecular associations between darkcolored acid-insoluble constituents, FA-like acid-soluble constituents, protein-like constituents, and polysaccharides bound by weak linkages.
\end{abstract}

Keywords: Acid-soluble constituents; Concentrated urea; Degree of humification; Fluorescence; Humic acid

\section{Background}

Soil organic matter is a complex, heterogeneous mixture resulting from the decomposition of plants, animals, and microorganisms in the soil environment. Soil humic acids (HAs) are usually extracted from soil using an alkaline solution and precipitated by acidification; therefore, these are considered to be heterogeneous in composition. Recent research has suggested that humic substances are

Correspondence: aoyamam@hirosaki-u.ac.jp

Faculty of Agriculture and Life Science, Hirosaki University, Hirosaki 036-8561, Japan

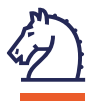

Springer

(c) 2015 Aoyama. This is an Open Access article distributed under the terms of the Creative Commons Attribution License (http://creativecommons.org/licenses/by/4.0), which permits unrestricted use, distribution, and reproduction in any medium, provided the original work is properly credited. formed due to the association between heterogeneous, relatively small molecules derived as a result of the degradation and decomposition of biological material. It is considered that the constituent molecules are bound by weak linkages, such as hydrogen-bonding and hydrophobic interactions [1-3].

Our previous study on two-dimensional (2-D) electrophoresis of HAs in the presence of $7 \mathrm{M}$ urea showed that the HAs were separated into their constituents with different charge characteristics and molecular sizes [4]. In that study, the $7 \mathrm{M}$ urea was used to facilitate the dissociation of HA constituents by disrupting the hydrogen- 
bonding and hydrophobic interactions $[1,5,6]$. However, we observed a low recovery of organic carbon in the precipitates after acidification to $\mathrm{pH}$ 1.0, indicating the dissolution of a significant quantity of HAs in the acid solution upon being subjected to electrophoresis [4].

We further subjected the HAs to polyacrylamide gel electrophoresis (PAGE) in the presence of $7 \mathrm{M}$ urea, using a preparative electrophoresis system [7]. Acidification of the electrophoretic fractions resulted in the separation of acid-soluble constituents from the dark-colored precipitates. A part of the acid-soluble constituents could be recovered by adsorption onto DAX-8 resin. The degree of humification was higher in the precipitates and lower in the acid-soluble DAX-8-adsorbed constituents, when compared to the corresponding whole HA. Thus, our previous studies have demonstrated that acid-soluble HA constituents can be dissociated by electrophoresis in the presence of concentrated urea.

Concentrated urea enhances the solvation capacity of alkaline solution, leading to the use of an alkaline concentrated urea solution in the extraction of humin from soils [8]. Concentrated urea could also be used in the fractionation of HAs into constituents displaying different chemical properties, using size exclusion chromatography $[1,9,10]$. Furthermore, soil HA constituents with different fluorescent properties were separated by ultrafiltration in the presence of concentrated urea $[11,12]$. The acid-soluble constituents can be dissociated by acidification after dissolution in alkaline medium [13]. However, the abovementioned findings suggested that the dissociation of acid-soluble constituents from soil HAs was attributable to the action of concentrated urea.

The purpose of this study was to investigate the effect of concentrated urea on the dissociation of acid-soluble constituents from soil HAs. Three soil HA samples were solubilized in $0.1 \mathrm{M} \mathrm{NaOH}$ containing $7 \mathrm{M}$ urea and precipitated by acidification to $\mathrm{pH}$ 1.0. The supernatant solutions were further separated into the DAX-8-adsorbed and DAX-8-non-adsorbed fractions. The fractionated constituents were characterized by degree of humification, high-performance size exclusion chromatography (HPSEC) with UV and fluorescence detections, threedimensional excitation-emission matrix (3-D EEM) fluorescence spectroscopy, and diffuse reflectance infrared Fourier transform (DRIFT) spectroscopy.

\section{Materials and methods Preparation of HAs}

The HAs used in this study were prepared from a Fluvisol (Fujisaki HA) and an Andosol (Takizawa HA) and purchased from the Japanese Humic Substances Society (Dando HA). The Fujisaki and Takizawa HAs were extracted twice from the soil samples containing $500 \mathrm{mg}$ of organic carbon with $150 \mathrm{~mL}$ of $0.1 \mathrm{M} \mathrm{NaOH}$ under $\mathrm{N}_{2}$ by intermittent shaking for $24 \mathrm{~h}$ and were separated by acidification to $\mathrm{pH} 1.0$ with $\mathrm{HCl}$. The HA precipitates were obtained by centrifugation at $10,000 \times g$ for $30 \mathrm{~min}$ and dissolved in $150 \mathrm{~mL}$ of $0.1 \mathrm{M} \mathrm{NaOH}$ containing $0.3 \mathrm{M} \mathrm{KCl}$, then precipitated again by acidification to $\mathrm{pH} 1.0$ with $\mathrm{HCl}$. The dissolutionprecipitation cycle was repeated twice. The resultant precipitates were suspended in a $0.1 \mathrm{M} \mathrm{HCl} / 0.3 \mathrm{M} \mathrm{HF}$ solution and shaken overnight. This step was repeated three times to minimize the ash content. The suspension was dialyzed against ultrapure water and freeze-dried. The Dando HA is the standard HA provided by the Japanese Humic Substances Society, and the details were reported elsewhere [14]. The elemental compositions of the HA samples used are presented in Table 1.

\section{Fractionation with an alkaline concentrated urea solution}

Forty milligrams of the HA samples was dissolved in $40 \mathrm{~mL}$ of $0.1 \mathrm{M} \mathrm{NaOH}$ containing $7 \mathrm{M}$ urea and left standing for $16 \mathrm{~h}$ at $25^{\circ} \mathrm{C}$ under $\mathrm{N}_{2}$, then acidified with $\mathrm{HCl}$ to reach a $\mathrm{pH}$ of 1.0. The dark-colored precipitates were obtained by centrifugation at $10,000 \times g$ for $10 \mathrm{~min}$ and washed four times with $0.01 \mathrm{M} \mathrm{HCl}$ and once with ultrapure water. The resultant precipitates were freezedried and designated as the precipitated fraction. The supernatant and the washings were combined and passed through a column containing DAX-8 resin (Supelco, Bellefonte, PA, USA). The column was washed with $0.1 \mathrm{M}$ $\mathrm{HCl}$ followed by ultrapure water. The pass-through solution of the DAX-8 column and the washings were combined and dialyzed in a Spectra/Por 7 membrane tubing (nominal molecular weight cutoff of $1000 \mathrm{Da}$; Spectra/Por, Rancho Dominguez, CA, USA) against ultrapure water, and the dialysate was designated as the DAX-8-nonadsorbed fraction $(>1 \mathrm{kDa})$. The fraction was concentrated to $10 \mathrm{~mL}$ using a rotary evaporator at $40^{\circ} \mathrm{C}$. The concentrated solution was divided into five $2-\mathrm{mL}$ portions and freeze-dried. The constituents adsorbed onto the DAX-8 resin were eluted with $0.1 \mathrm{M} \mathrm{NaOH}$ and passed through a cation exchange resin $\left(\mathrm{H}^{+}\right.$form $)$column. This was designated as the DAX-8-adsorbed fraction. The fraction was concentrated to $10 \mathrm{~mL}$ using a rotary evaporator at $40{ }^{\circ} \mathrm{C}$, divided into five 2-mL portions, and freeze-dried. As a control treatment, $40 \mathrm{mg}$ of the HA samples was dissolved in $40 \mathrm{~mL}$ of $0.1 \mathrm{M} \mathrm{NaOH}$ (without urea) and treated in the same manner, with the exception that the DAX-8-

\begin{tabular}{|c|c|c|c|c|c|c|}
\hline \multirow{2}{*}{$\begin{array}{l}\text { Humic } \\
\text { acid }\end{array}$} & \multirow{2}{*}{$\begin{array}{l}\text { Ash }^{a} \\
\left(\mathrm{~g} \mathrm{~kg}^{-1}\right)\end{array}$} & \multicolumn{5}{|c|}{ Elemental composition ${ }^{\mathrm{b}}\left(\mathrm{g} \mathrm{kg}^{-1}\right)$} \\
\hline & & $\mathrm{C}$ & $\mathrm{H}$ & $\mathrm{N}$ & $S$ & $\mathrm{O}$ \\
\hline Fujisaki & 9.6 & 530 & 51.7 & 56.2 & 7.4 & 355 \\
\hline Dando & 6.7 & 530 & 52.5 & 44.9 & 2.9 & 369 \\
\hline Takizawa & 6.7 & 568 & 41.0 & 39.5 & 2.5 & 349 \\
\hline
\end{tabular}

${ }^{\mathrm{a}}$ On a moisture-free basis

${ }^{\mathrm{b}}$ On a moisture and ash-free basis 
non-adsorbed portion was used only for the analysis of organic carbon concentration without dialyzing and freezedrying.

\section{Determination of organic carbon}

For the precipitated fraction, $1 \mathrm{mg}$ of the freeze-dried sample was dissolved in $800 \mu \mathrm{L}$ of $0.1 \mathrm{M} \mathrm{NaOH}$ and a part of the solution was mixed with four times the volume of $0.067 \mathrm{M}$ potassium dihydrogen phosphate [15], vortexed, and then allowed to stand at room temperature overnight to remove inorganic carbon. The total organic carbon concentration of the mixture was determined using a total organic carbon analyzer (TOC- $\mathrm{V}_{\mathrm{E}}$; Shimadzu Co., Ltd., Kyoto, Japan). For the DAX-8adsorbed and DAX-8-non-adsorbed fractions, a divided portion of the fractions was dissolved in $800 \mu \mathrm{L}$ of $0.1 \mathrm{M} \mathrm{NaOH}$ and determined the concentration of total organic carbon in the same manner as described above.

\section{Evaluation of humification degree}

The absorbances of the precipitated and DAX-8-adsorbed fractions used for the analysis of total organic carbon content at 400 and $600 \mathrm{~nm}$ were determined using a V-630 spectrophotometer (JASCO Corp., Tokyo, Japan). The degree of humification of the precipitated and DAX-8adsorbed fractions was evaluated based on the $A_{600} / C$ and $\log \left(A_{400} / A_{600}\right)$ values, where $A_{400}, A_{600}$, and $C$ denoted the absorbance at 400 and $600 \mathrm{~nm}$ and the carbon concentration $\left(\mathrm{mg} \mathrm{mL}^{-1}\right)$, respectively [15].

\section{HPSEC}

The molecular size distribution was estimated by HPSEC as described in our previous study [4]. For HPSEC, the freeze-dried samples were dissolved in $1 \mathrm{~mL}$ of $0.1 \mathrm{M}$ $\mathrm{NaOH}$ and then neutralized by passing through a cationexchange cartridge $\left(\mathrm{H}^{+}\right.$form; Dionex OnGuard II $\mathrm{H}$, Thermo Fisher Scientific K.K., Yokohama, Japan). The solution was adjusted to the same composition as the mobile phase and then filtered through a $0.45-\mu \mathrm{m}$ membrane filter. A $100-\mu \mathrm{L}$ portion of the sample solution was injected. The chromatograms were monitored by UV absorption using a photodiode array detector (MD-2018, JASCO Corp., Tokyo, Japan) and by fluorescence at excitation and emission wavelengths of 460 and $520 \mathrm{~nm}$, respectively, using a fluorescence detector (FP-920, JASCO Corp., Tokyo, Japan). To estimate the molecular weight (MW), the column was calibrated using polyethylene glycols as the MW standards [7].

\section{3-D EEM fluorescence spectroscopy}

The freeze-dried sample was dissolved in $1 \mathrm{~mL}$ of $0.1 \mathrm{M}$ $\mathrm{NaOH}$ and neutralized by passing through a cationexchange cartridge $\left(\mathrm{H}^{+}\right.$form; Dionex OnGuard II $\mathrm{H}$, Thermo Fisher Scientific K.K., Yokohama, Japan). The solution was diluted with ultrapure water and added with $0.05 \mathrm{M}$ phosphate buffer ( $\mathrm{pH} 8.0)$ to a final concentration of $5 \mathrm{mg}$ organic carbon $\mathrm{L}^{-1}$ in $0.01 \mathrm{M}$ phosphate buffer. The 3-D EEM fluorescence spectra were recorded in a 1-cm quartz cell using a FP-8300 scanning spectrofluorometer (JASCO Corp., Tokyo, Japan) equipped with an automatic higher order diffraction cut filter. The spectra were recorded over the excitation and emission wavelength ranges of $200-550 \mathrm{~nm}$ and $250-600 \mathrm{~nm}$, respectively, and then corrected for instrumental bias according to the manufacturer's method. Inner-filter effect was corrected using the following equation $[16,17]$ :

$$
\mathrm{Em}_{\text {real }}=\mathrm{Em}_{\mathrm{obs}} \times 10^{b \times(A \mathrm{ex}+A \mathrm{em})}
$$

where $\mathrm{Em}_{\mathrm{obs}}$ was the observed fluorescence intensity, $\mathrm{Em}_{\text {real }}$ denoted the fluorescence in the absence of selfabsorption, $b$ was $0.5 \mathrm{~cm}$, and the path length to the center of the cell for both excitation and emission, $A_{\text {ex }}$ and $A_{\mathrm{em}}$, denoted the absorbance at excitation and emission wavelengths, respectively. The Raman scatter effect was minimized by subtracting EEM spectrum of $0.01 \mathrm{M}$ phosphate buffer ( $\mathrm{pH}$ 8.0). The relative fluorescence intensity was expressed as the quinine sulfate unit (QSU) using the fluorescence intensity of a quinine sulfate solution $\left(0.01 \mathrm{mg} \mathrm{L}^{-1}\right.$ in $\left.0.05 \mathrm{M} \mathrm{H}_{2} \mathrm{SO}_{4}\right)$ at the excitation/ emission wavelengths $\left(\lambda_{\mathrm{ex}} / \lambda_{\mathrm{em}}\right)=350 / 450 \mathrm{~nm}$.

\section{DRIFT spectroscopy}

DRIFT spectra of the fractions were recorded using an FT/IR-4100 spectrometer (JASCO Corp., Tokyo, Japan) equipped with a DR-81 diffuse reflectance accessory (JASCO Corp., Tokyo, Japan). The freeze-dried samples were thoroughly mixed with 50-100 times the amount of potassium bromide (FT-IR grade; Wako Pure Chemical Industries, Ltd., Osaka, Japan) in an agate mortar and pestle and placed in an aluminum sample cup. Spectra were collected from 4000 to $800 \mathrm{~cm}^{-1}$ and averaged over 100 scans and then transformed into Kubelka-Munk units [18]. The resolution was set at $4 \mathrm{~cm}^{-1}$. To identify the principal bands that contribute to the more complex band resulting from overlapping features, Fourier selfdeconvolution (FSD) was performed for the wavenumber region between 1800 and $800 \mathrm{~cm}^{-1}$, using the JASCO FT-IR software provided with the spectrometer.

\section{Results and discussion}

\section{Distribution of HA constituents among the fractions}

The dissolution of HAs in $0.1 \mathrm{M} \mathrm{NaOH}$ alone and subsequent acidification resulted in the dissociation of acidsoluble constituents from the dark-colored precipitates (Fig. 1). The proportion of the organic carbon, recovered as precipitates, was $84 \%$ for the Fujisaki HA sample, $84 \%$ for the Dando HA sample, and $92 \%$ for the Takizawa HA 


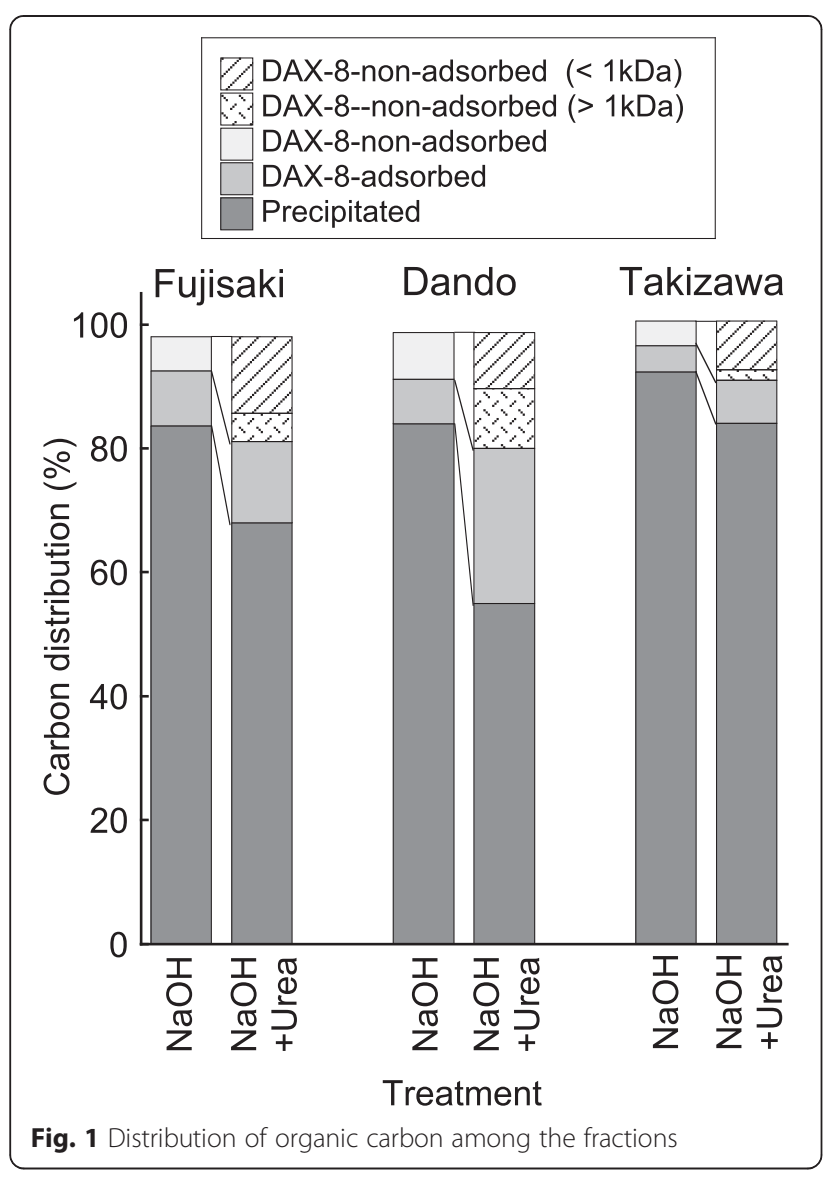

sample. Among the acid-soluble constituents, the browncolored constituents were recovered by adsorption onto the DAX-8 resin (DAX-8-adsorbed fraction). The organic carbon in the DAX-8-adsorbed fraction was approximately half of that in the acid-soluble constituents. Dissolution in alkaline concentrated urea enhanced the dissociation of acid-soluble constituents. The precipitated fraction accounted for $68 \%$ of the total organic carbon in the Fujisaki HA sample, $54 \%$ in the Dando HA sample, and $84 \%$ in the Takizawa HA sample. The proportion of the brown-colored DAX-8-adsorbed fraction was significantly higher than when treated with $0.1 \mathrm{M} \mathrm{NaOH}$. The DAX-8-non-adsorbed fraction was nearly colorless, and the proportion of the total organic carbon in this fraction was also increased by treatment with concentrated urea. However, a substantial part was lost during the dialysis (Fig. 1). The proportion of organic carbon in the unrecovered part was estimated to be 12,9 , and $8 \%$ for the Fujisaki HA, Dando HA, and Takizawa HA samples, respectively.

Our previous study has demonstrated that acid-soluble constituents were separated from HAs during preparative PAGE in the presence of concentrated urea [7]. This study further revealed that the dissociation of acid-soluble constituents from HAs occurred when the HAs were dissolved in alkaline concentrated urea solution, followed by the acidification of the solution. Moreover, it was confirmed that the brown-colored acid-soluble constituents, as well as the nearly colorless acid-soluble constituents, were dissociated from HAs by concentrated urea treatment. Concentrated urea is considered to disrupt the hydrogen-bonding and hydrophobic interactions $[1,12,19]$. Therefore, the dissociation of HA constituents observed in this study can be attributed to the disruption of the hydrogen-bonding and hydrophobic interactions triggered by concentrated urea.

\section{Humification degree of the fractions}

In order to evaluate the humification degree of the precipitated and DAX-8-adsorbed fractions, $A_{600} / C$ and $\log \left(A_{400} / A_{600}\right)$ values were used (Fig. 2). An increase in the $A_{600} / C$ value and a decrease in the $\log \left(A_{400} / A_{600}\right)$ value were known to indicate an increase in the degree of humification of HA [15]. The degree of humification used here is synonymous with the degree of darkening $[15,20]$. Kumada [20] classified HAs into four types according to their optical properties: type A HAs are the most humified, type B HAs are the intermediates between type A and type Rp, type Rp HAs are the least humified, and type P HAs are moderately humified, as indicated in Fig. 2.

The DAX-8-adsorbed fraction exhibited a lower $A_{600} /$ $C$ value and a higher $\log \left(A_{400} / A_{600}\right)$ value compared to the corresponding whole HA sample irrespective of treatment with concentrated urea. The reverse was true for the precipitated fraction. These results indicated that the acid-soluble constituents of HA were characterized by a low degree of humification and that their dissociation from HA resulted in an increase in the humification degree of precipitated constituents. These findings were in agreement with our previous study, where preparative PAGE of HAs was carried out in the presence of concentrated urea [7]. The degree of humification of the precipitated fraction was significantly higher when treated with alkaline concentrated urea. This was attributed to the higher dissociation of acid-soluble constituents in the presence of concentrated urea.

\section{Molecular size distribution of the fractions}

The molecular size distributions were estimated using HPSEC with UV detection at $280 \mathrm{~nm}$ (Fig. 3). The molecular size distributions of the whole samples of Fujisaki and Dando HAs were similar but differed largely from that of Takizawa HA. An intense peak was observed at the void volume $\left(V_{0}\right)$, and a broad peak was eluted in the MW region of $2-20 \mathrm{kDa}$ for the Fujisaki and Dando HA whole samples. In contrast, for the Takizawa HA, a broad peak was eluted at a MW of $2 \mathrm{kDa}$. Thus, the 


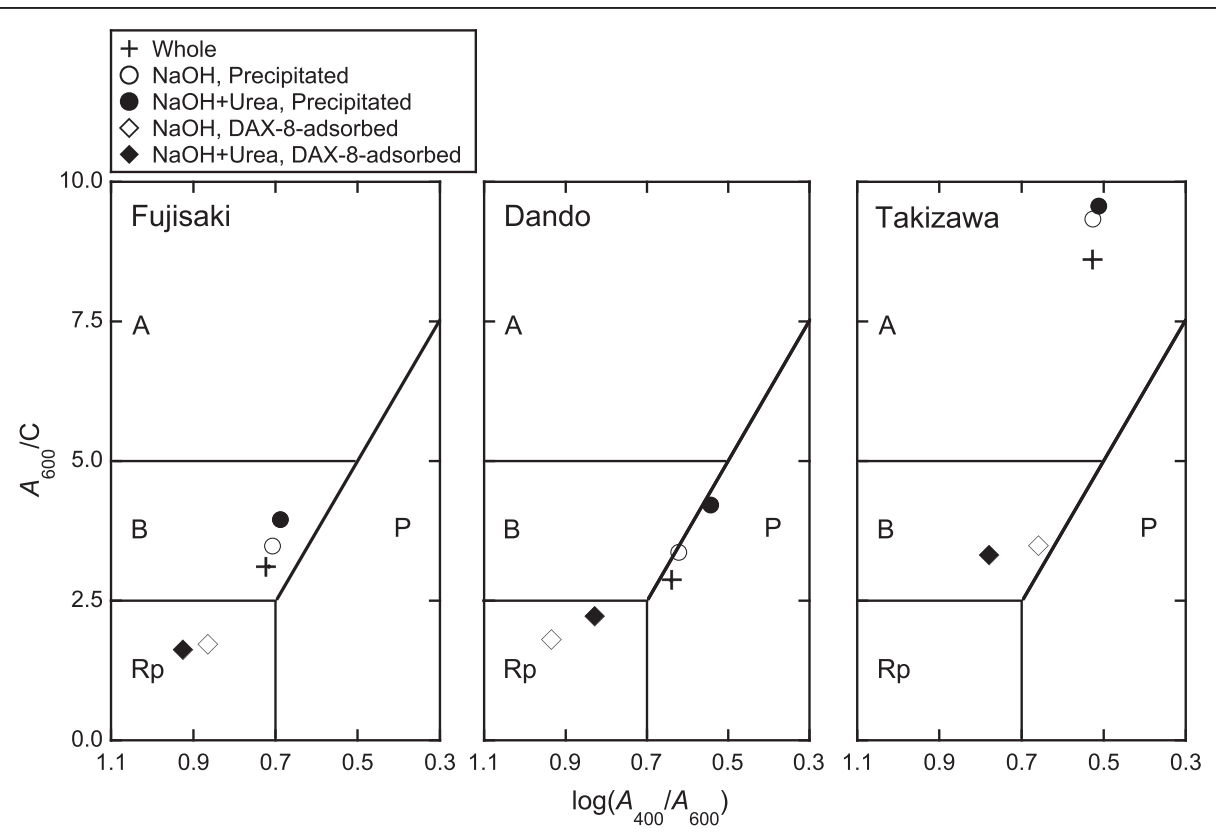

Fig. $2 \log \left(A_{400} / A_{600}\right)$ versus $A_{600} / C$ diagram of precipitated and DAX-8-adsorbed fractions. The symbols $(A, B, P$, and $R p)$ in the figure indicate the types of HAs in Kumada's classification system [20]. The degree of humification is higher in the order $A>B$ or $P>R p$

Takizawa HA consisted mainly of relatively small molecular size constituents compared to the Fujisaki and Dando HAs.

For control treatment, the molecular size distribution of the precipitated fraction was similar to that of the corresponding whole HA, while the peak of DAX-8adsorbed fraction was observed at a MW of $2 \mathrm{kDa}$ irrespective of the HAs used. The molecular size of the DAX-8-adsorbed fraction was similar to those of fulvic acids (FAs) [21]. Higher molecular size distributions were obtained from the precipitated fractions treated with alkaline urea compared to those having received the treatment with $0.1 \mathrm{NaOH}$ alone. This was attributed

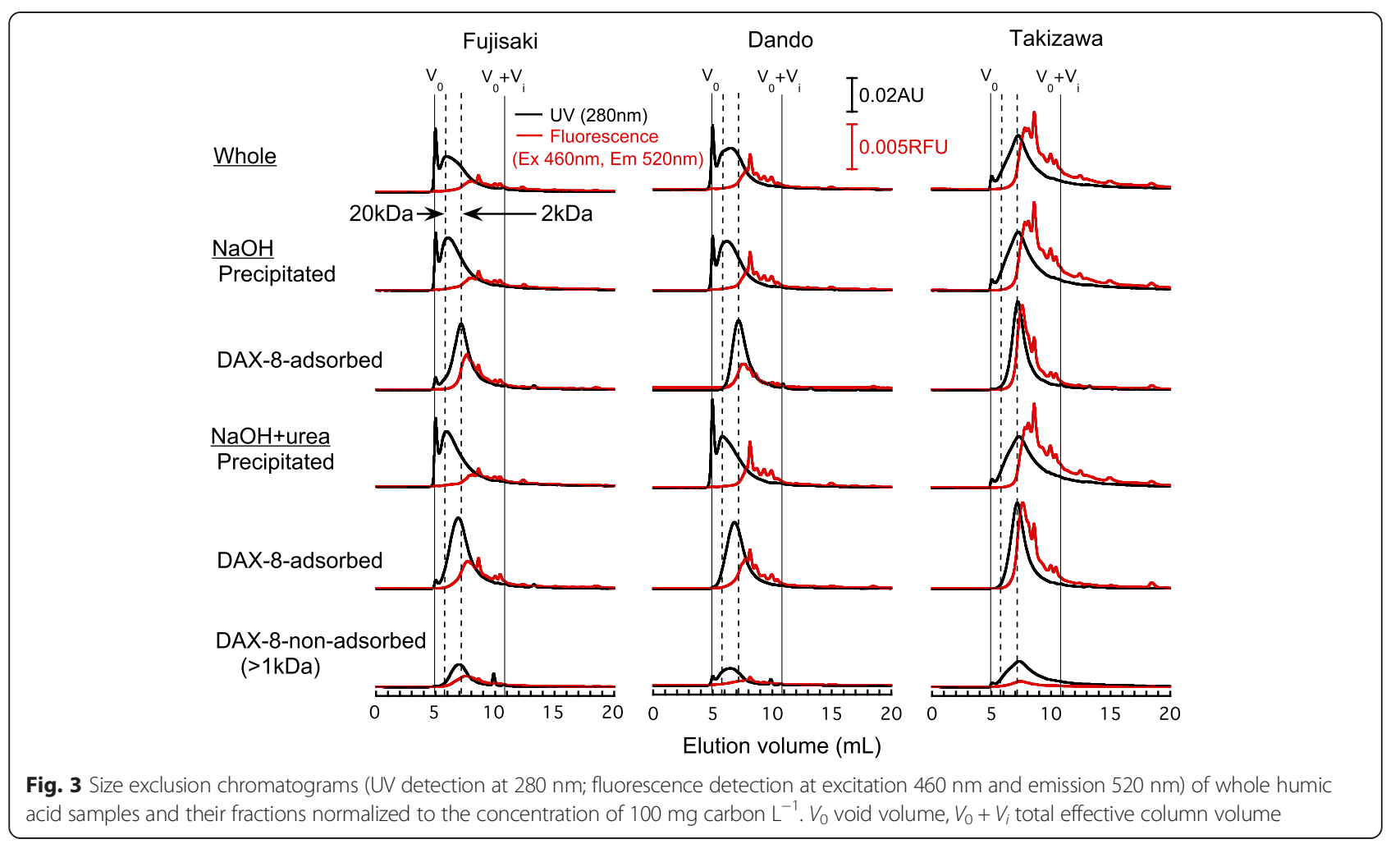


to the higher dissociation of DAX-8-adsorbed and DAX8-non-adsorbed fractions when treated with concentrated urea. The molecular size of the DAX-8-adsorbed fraction was similar to (in the case of Takizawa HA) or larger than (Fujisaki and Dando HAs) those observed for the control treatment. The DAX-8-non-adsorbed fraction $(>1 \mathrm{kDa})$ showed a similar molecular size to that observed for the DAX-8-adsorbed fraction; however, the intensity of the peak was observed to be relatively lower. The molecular sizes of the acid-soluble constituents dissociated by concentrated urea treatment were similar to those dissociated by preparative PAGE in the presence of concentrated urea [7].

When detected by fluorescence at $\lambda_{\mathrm{ex}} / \lambda_{\mathrm{em}}=460 / 520 \mathrm{~nm}$, the peaks for whole HAs were eluted over a wide range of elution volumes (Fig. 3), as observed in previous studies $[21,22]$. However, the intensities of the fluorescencedetected peaks varied with the HA samples (lowest in the Fujisaki HA and highest in the Takizawa HA).

Fluorescence-detected peaks were observed for all the fractions (Fig. 3), with the peak intensity being relatively low in the DAX-8-non-adsorbed fraction. This indicated that the fluorescent substances were mainly partitioned into both the precipitated and DAX-8-adsorbed fractions. The fluorescence-detected peaks of the DAX-8-adsorbed and DAX-8-non-adsorbed fractions were eluted in advance of that of the precipitated fraction. Therefore, the elution profile of the precipitated fraction lacked the largest molecular size components, compared to the corresponding whole HA. This indicates that the molecular sizes of the fluorescent substances in the DAX-8-adsorbed and DAX8-non-adsorbed fractions were higher than those in the precipitated fractions.

\section{Fluorescent properties of the fractions}

3-D EEM fluorescence spectroscopy was utilized to investigate the fluorescent properties of whole HAs and their fractions. The 3-D EEM contour plots are shown in Fig. 4, and the fluorescence maxima and their relative intensities have been summarized in Table 2.

The fluorescence peaks at $\lambda_{\mathrm{ex}} / \lambda_{\mathrm{em}}=265-275 / 505-540 \mathrm{~nm}$ (H1) and 430-460/510-540 nm (H4) were observed for all the whole HA samples, with the relative fluorescence intensities varying with each HA. In addition, the fluorescence peak was observed at $\lambda_{\mathrm{ex}} / \lambda_{\mathrm{em}}=360-365 / 505 \mathrm{~nm}$ (H3) for the Fujisaki and Dando HA samples and at $\lambda_{\mathrm{ex}} /$ $\lambda_{\mathrm{em}}=310 / 510 \mathrm{~nm}$ (H2) for the Dando HA sample. The relative fluorescence intensities (QSU) were significantly high in the Takizawa HA compared to the other HAs. This is in agreement with the results of HPSEC with fluorescence detection. Our previous studies [4, 7, 21-23] showed that the fluorescent substances were considerably more in Andosol HAs than in HAs prepared from the other types of soils.
For the control treatment, the fluorescence maxima and relative intensities of the precipitated fractions were nearly identical to those observed for the whole HA samples. In contrast, the positions of fluorescence peaks of the DAX-8-adsorbed fraction (F1-3) did not coincide with those of the precipitated fraction and the whole HA, with the excitation and emission wavelengths being shorter for the former compared to the latter. The positions of the fluorescence maxima resembled those of FAs [24]. However, the fluorescence maxima and relative fluorescence intensities of the DAX-8-adsorbed fraction were similar between the different HA samples.

For the treatment with concentrated urea, the fluorescence maxima and relative intensities of the precipitated fraction were observed to be identical to those of the whole HA and the precipitated fraction of the control treatment. The fluorescence maxima and relative fluorescence intensities of the DAX-8-adsorbed fraction were similar to those observed in the DAX-8-adsorbed fraction from the control treatment. However, a fluorescence peak at $\lambda_{\mathrm{ex}} / \lambda_{\mathrm{em}}=275 / 315 \mathrm{~nm}$ (P) was observed for the DAX-8-adsorbed fraction of the Dando HA sample, which was attributed to the fluorescence of protein-like substances $[25,26]$.

The position of the major fluorescence maximum of DAX-8-non-adsorbed fraction varied for each HA sample: it was observed at $\lambda_{\mathrm{ex}} / \lambda_{\mathrm{em}}=270 / 465 \mathrm{~nm}$ (F2) for the Fujisaki HA sample, at $215 / 430 \mathrm{~nm}$ (F1) for the Dando HA sample, and at $225 / 440 \mathrm{~nm}$ (F1) for the Takizawa HA sample. All spectra were associated with a secondary maximum (P) at $\lambda_{\mathrm{ex}} / \lambda_{\mathrm{em}}=280 / 330 \mathrm{~nm}$ (Fujisaki HA) or 270/330 nm (Dando and Takizawa HAs). These secondary maxima were attributed to the fluorescence of proteinlike substances $[25,26]$.

Richard et al. [12] fractionated a soil HA sample by ultrafiltration, in the presence of $7 \mathrm{M}$ urea. They reported that the fraction with molecular size 0.5-1 kDa exhibited an emission maxima at a shorter wavelength compared to the fractions with molecular size $>1 \mathrm{kDa}$. This indicated that the relatively smaller HA constituents with an emission maximum at a shorter wavelength were dissociated in the presence of concentrated urea, an observation that was confirmed by the present results.

\section{Infrared spectroscopy of the fractions}

Figure 5 shows the DRIFT spectra of the whole HAs and their fractions. The spectrum of the precipitated fraction was similar to that of the corresponding whole HA, irrespective of treatment with concentrated urea. In contrast, the spectra of the DAX-8-adsorbed and DAX-8-nonadsorbed fractions were different from their whole samples and precipitated fractions. Absorption peaks at 2850 and $2920 \mathrm{~cm}^{-1}$, assigned to the symmetric and asymmetric methylene stretching bands in aliphatic chains 


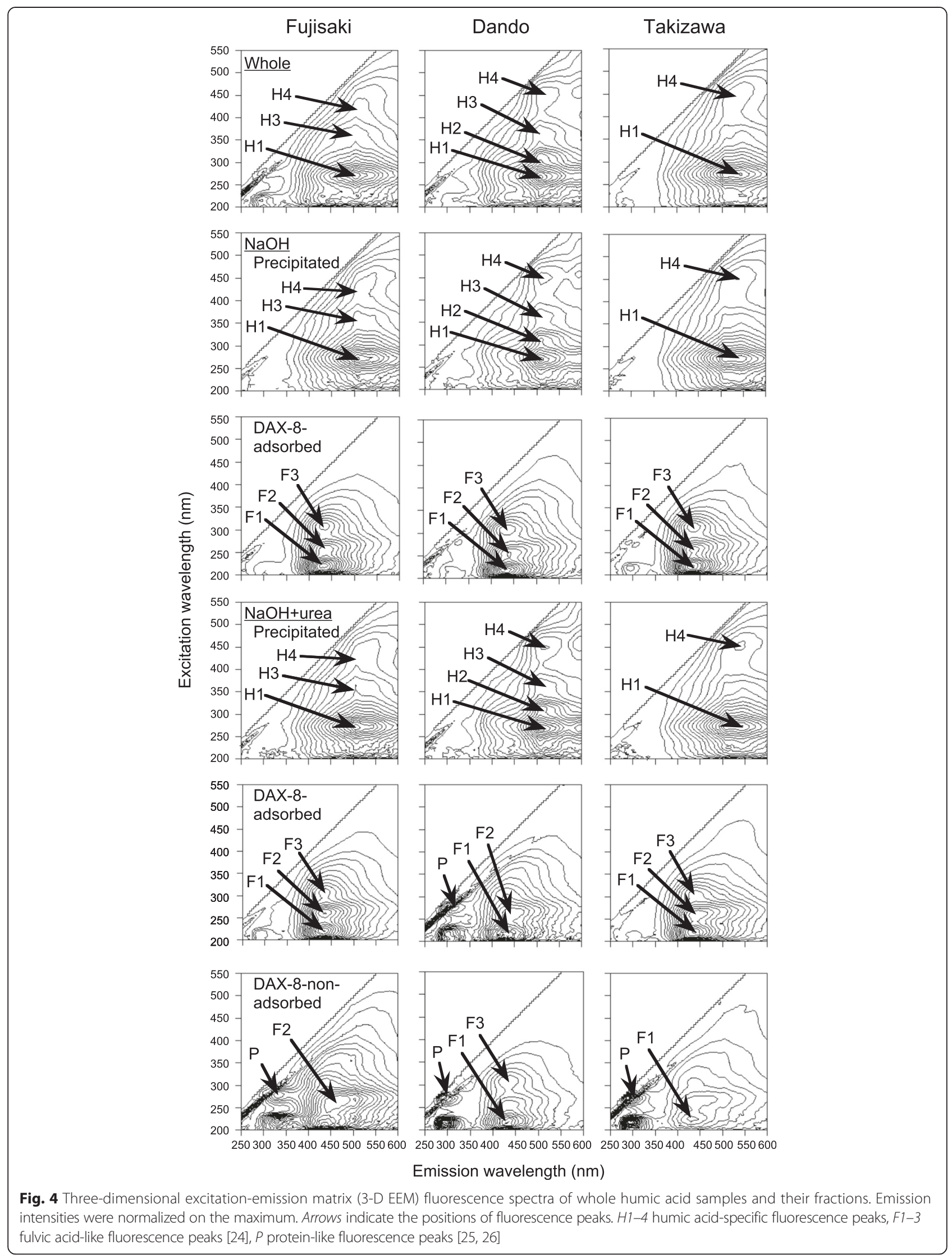


Table 2 Positions and relative intensities of the fluorescence peaks

\begin{tabular}{|c|c|c|c|c|c|c|c|}
\hline \multirow[t]{2}{*}{ Fraction } & \multirow[t]{2}{*}{ Peak $^{a}$} & \multicolumn{2}{|l|}{ Fujisaki } & \multicolumn{2}{|l|}{ Dando } & \multicolumn{2}{|l|}{ Takizawa } \\
\hline & & $\lambda_{\mathrm{ex}} / \lambda_{\mathrm{em}}^{\mathrm{b}}$ & QSU & $\lambda_{\mathrm{ex}} / \lambda_{\mathrm{em}}^{\mathrm{b}}$ & QSU & $\lambda_{\mathrm{ex}} / \lambda_{\mathrm{em}}^{\mathrm{b}}$ & QSU \\
\hline \multirow[t]{4}{*}{ Whole } & $\mathrm{H} 1$ & $270 / 505$ & 65 & $265 / 505$ & 54 & $275 / 540$ & 134 \\
\hline & $\mathrm{H} 2$ & - & - & $310 / 510$ & 36 & - & - \\
\hline & $\mathrm{H} 3$ & $365 / 505$ & 27 & $360 / 505$ & 23 & - & - \\
\hline & $\mathrm{H} 4$ & $430 / 510$ & 18 & $460 / 515$ & 16 & $450 / 540$ & 48 \\
\hline \multicolumn{8}{|l|}{$\mathrm{NaOH}$} \\
\hline \multirow[t]{4}{*}{ Precipitated } & $\mathrm{H} 1$ & $270 / 505$ & 54 & $270 / 510$ & 56 & $275 / 545$ & 180 \\
\hline & $\mathrm{H} 2$ & - & - & $310 / 510$ & 38 & - & - \\
\hline & $\mathrm{H} 3$ & $365 / 505$ & 22 & $365 / 505$ & 23 & - & - \\
\hline & $\mathrm{H} 4$ & $430 / 505$ & 16 & $450 / 510$ & 18 & $450 / 535$ & 57 \\
\hline \multirow[t]{3}{*}{ DAX-8-adsorbed } & F1 & $220 / 430$ & 107 & $220 / 430$ & 100 & $220 / 430$ & 104 \\
\hline & F2 & $255 / 435$ & 77 & $255 / 440$ & 71 & $255 / 435$ & 80 \\
\hline & F3 & $310 / 435$ & 57 & $310 / 435$ & 55 & $310 / 435$ & 59 \\
\hline \multicolumn{8}{|l|}{$\mathrm{NaOH}+$ urea } \\
\hline \multirow[t]{4}{*}{ Precipitated } & $\mathrm{H} 1$ & $270 / 505$ & 48 & $270 / 510$ & 69 & $275 / 545$ & 181 \\
\hline & $\mathrm{H} 2$ & - & - & $310 / 510$ & 48 & - & - \\
\hline & $\mathrm{H} 3$ & $360 / 505$ & 21 & $365 / 505$ & 27 & - & - \\
\hline & $\mathrm{H} 4$ & $430 / 505$ & 16 & $450 / 510$ & 21 & $450 / 540$ & 59 \\
\hline \multirow[t]{4}{*}{ DAX-8-adsorbed } & F1 & $220 / 435$ & 105 & $210 / 435$ & 96 & $220 / 435$ & 154 \\
\hline & F2 & $260 / 435$ & 89 & $260 / 440$ & 72 & $260 / 440$ & 127 \\
\hline & F3 & $305 / 435$ & 58 & - & - & $305 / 440$ & 81 \\
\hline & $P$ & - & - & $275 / 315$ & 32 & - & - \\
\hline \multirow[t]{4}{*}{ DAX-8-non-adsorbed (>1 kDa) } & F1 & - & - & $215 / 430$ & 30 & $225 / 440$ & 29 \\
\hline & F2 & $270 / 465$ & 31 & - & - & - & - \\
\hline & F3 & - & - & $310 / 435$ & 15 & - & - \\
\hline & P & $280 / 330$ & 14 & $270 / 310$ & 12 & 270/310 & 26 \\
\hline
\end{tabular}

QSU quinine sulfate unit

andicated in Fig. 4

${ }^{\mathrm{b}}$ Excitation/emission wavelengths ( $\left.\mathrm{nm}\right)$

[27], respectively, were observed in most of the spectra. The peaks were intense in the spectra obtained for the Fujisaki and Dando HAs, especially in the precipitated and DAX-8-non-adsorbed fractions. Absorption bands in the wavenumber region between 800 and $1800 \mathrm{~cm}^{-1}$ were observed to be overlapping. Therefore, the FSD was applied in order to enhance the resolution of the absorption bands (Fig. 6).

For the whole HAs, the peak observed at $1720 \mathrm{~cm}^{-1}$, assigned to the $\mathrm{C}=\mathrm{O}$ stretching of carboxyl group, was more intense in the Takizawa HA. On the other hand, the peaks at around 1670 and $1540 \mathrm{~cm}^{-1}$, attributed to the amide I and amide II bands of proteinous moieties [28], and at $1510 \mathrm{~cm}^{-1}$ (vibrations of aromatic moieties in lignin) [29-31], $1410 \mathrm{~cm}^{-1}$ (the symmetric carboxylate stretching) [28], and 1080 and $1030 \mathrm{~cm}^{-1}$, attributed to $\mathrm{C}-\mathrm{H}$ stretching of polysaccharide moieties [28], were observed to be more intense in the Fujisaki and Dando HA samples.
The control and concentrated urea-treated precipitated fractions exhibited similar spectra to those displayed by the corresponding whole HA. In contrast, the control-treated DAX-8-adsorbed fraction showed a similar spectrum, irrespective of the type of HA. The spectrum was characterized by a more intense peak representing the carboxyl group at $1720 \mathrm{~cm}^{-1}$ and a less intense peak at $1600 \mathrm{~cm}^{-1}$, attributed to the $\mathrm{C}=\mathrm{C}$ stretching in aromatic rings [28] compared to the whole HAs. These spectral characteristics were similar to that observed for FA [27, 32]. The DAX-8adsorbed fraction from the concentrated urea treatment displayed spectra with more intense peaks at 1670 and $1540 \mathrm{~cm}^{-1}$ due to the amide I and amide II bands, compared to those shown by the DAX-8-adsorbed fractions from the control treatment. The spectra of DAX-8-nonadsorbed fraction were characterized by prominent amide peaks at 1670 and $1540 \mathrm{~cm}^{-1}$ and by intense polysaccharide peaks at 1080 and $1030 \mathrm{~cm}^{-1}$. The presence of proteinous 


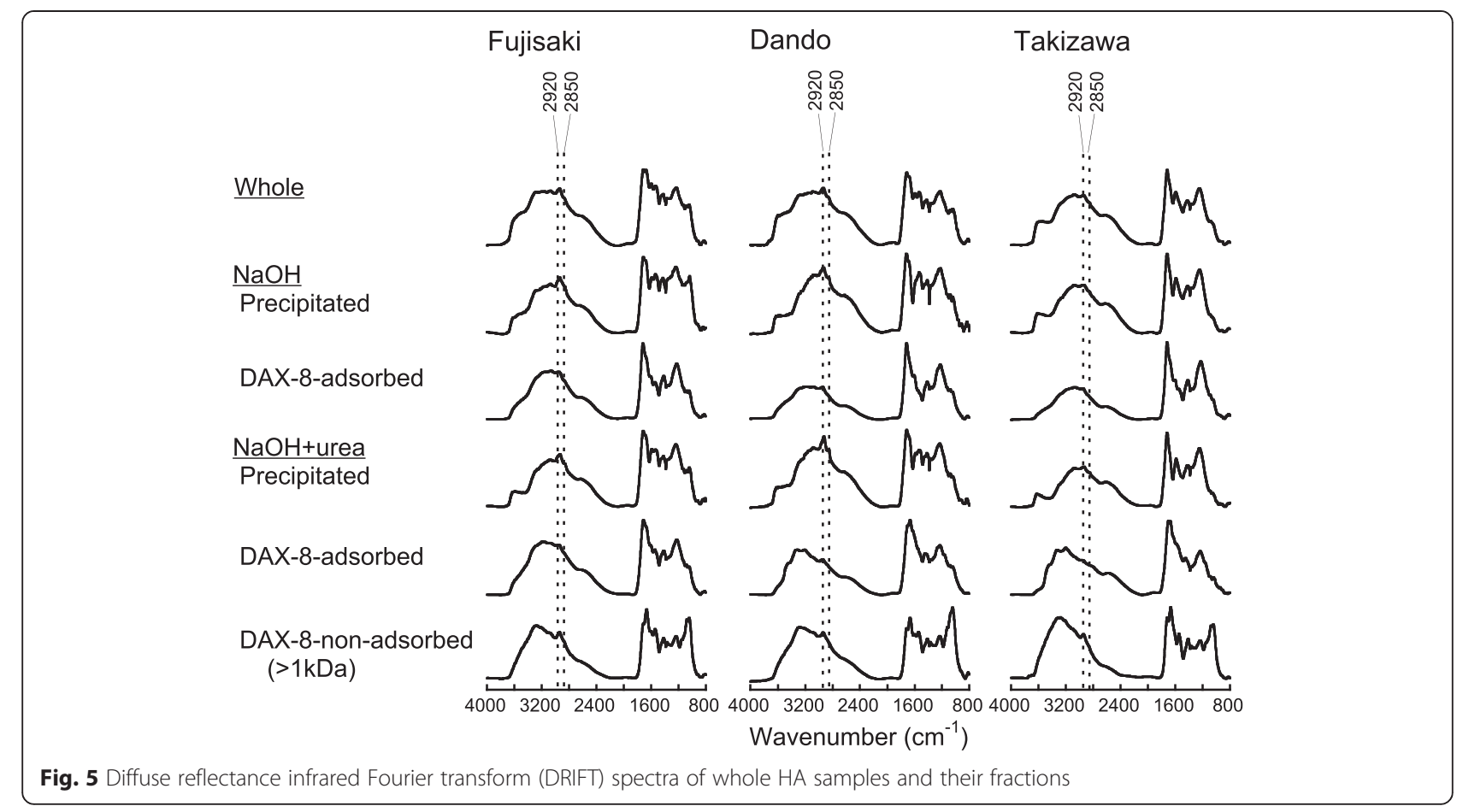

moieties in the acid-soluble constituents is in agreement with the results of 3-D EEM fluorescence spectroscopy.

\section{Conclusions}

The acid-soluble constituents of soil HAs obtained by treatment with concentrated urea were characterized by lower degrees of humification and smaller molecular sizes and displayed FA-like fluorescence. These features indicate that the acid-soluble constituents of soil HAs dissociated by concentrated urea treatment expressed similar properties to FAs. This was supported by the results of infrared spectroscopy. Infrared and fluorescence spectroscopies

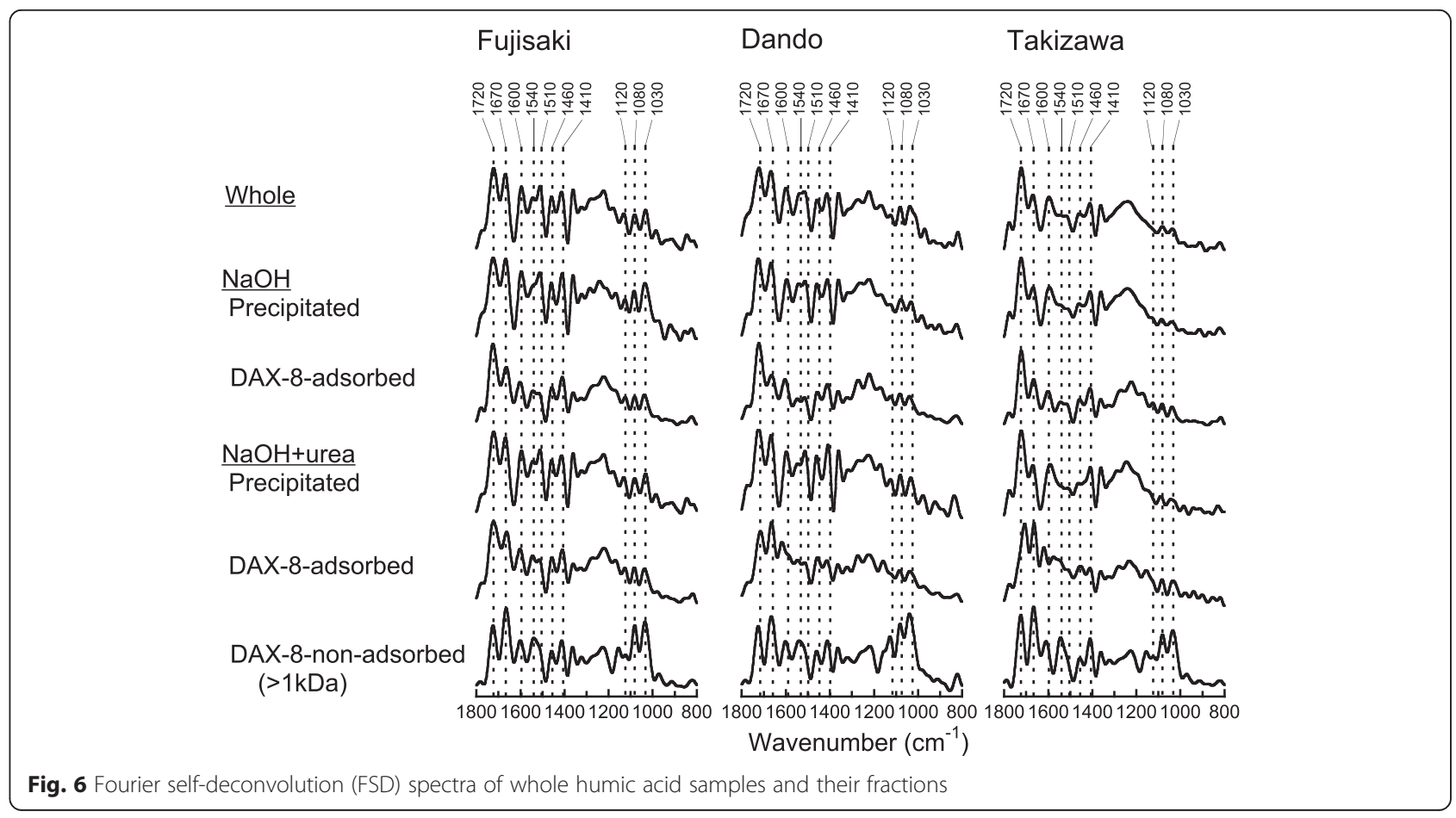


revealed that the acid-soluble constituents contained proteinous moieties and the DAX-8-non-adsorbed fraction was rich in polysaccharide moieties. In contrast, the humification degree of the precipitated fraction increased due to the separation of acid-soluble constituents. The precipitated fraction still contained smaller molecular size fluorescent substances. The present findings suggest that soil HAs are composed of dark-colored acid-insoluble constituents, FA-like acid-soluble constituents, protein-like constituents, and polysaccharides bound by weak linkages.

\section{Abbreviations}

3-D EEM: three-dimensional excitation-emission matrix; DRIFT: diffuse reflectance infrared Fourier transform; FA: fulvic acid; FSD: Fourier self-deconvolution; HA: humic acid; HPSEC: high-performance size exclusion chromatography; MW: molecular weight; PAGE: polyacrylamide gel electrophoresis.

\section{Competing interests}

The author declares that he has no competing interests.

\section{Acknowledgements}

This study was supported by Grant-in-Aid for Scientific Research (No. 26450072) from the Japan Society for the Promotion of Science (JSPS).

Received: 28 November 2014 Accepted: 10 June 2015

Published online: 30 June 2015

\section{References}

1. Piccolo A (2001) The supramolecular structure of humic substances. Soil Sci 166:810-832

2. Simpson AJ, Kingery WL, Hayes MHB, Spraul M, Humpfer E, Dvortsak P Kerssebaum R, Godejohann M, Hofmann M (2002) Molecular structures and associations of humic substances in the terrestrial environment Naturwissenschaften 89:84-88

3. Sutton R, Sposit G (2005) Molecular structure in soil humic substances: the new view. Environ Sci Technol 39:9009-9015

4. Karim S, Okuyama Y, Aoyama M (2013) Separation and characterization of the constituents of compost and soil humic acids by two-dimensional electrophoresis. Soil Sci Plant Nutr 57:130-141

5. Trubetskoj OA, Kudryavceva LY, Shirshova LT (1991) Characterization of soil humic matter by polyacrylamide gel electrophoresis in the presence of denaturating agents. Soil Biol Biochem 23:1179-1181

6. Trubetskoj OA, Trubetskaya OE, Khomutova TE (1992) Isolation, purification and some physico-chemical properties of soil humic substances fractions obtained by polyacrylamide gel electrophoresis. Soil Biol Biochem 24:893-896

7. Karim S, Aoyama M (2013) Fractionation of the constituents of soil humic acids by preparative polyacrylamide gel electrophoresis in the presence of concentrated urea. Soil Sci Plant Nutr 59:827-839

8. Song G, Hayes MHB, Novotny EH, Simpson AJ (2011) Isolation and fractionation of soil humin materials using alkaline urea and dimethylsulphoxide plus sulphuric acid. Naturwissenschaften 98:7-13

9. Francioso O, Montecchio D, Gioacchini P, Cavani L, Ciavatta C, Trubetskoj O, Trubetskaya O (2009) Structural differences of Chernozem soil humic acids SEC-PAGE fractions revealed by thermal (TG-DTA) and spectroscopic (DRIFT) analyses. Geoderma 152:264-268

10. Trubetskoj OA, Hatcher PG, Trubetskaya OE (2010) ${ }^{1} \mathrm{H}-\mathrm{NMR}$ and ${ }^{13} \mathrm{C}-\mathrm{NMR}$ spectroscopy of chernozem soil humic acid fractionated by combined size-exclusion chromatography and electrophoresis. Chem Ecol 26:315-325

11. Trubetskaya OE, Shaloiko LA, Demin DV, Marchenkov W, Proskuryakov II, Coelho C, Trubetskoj OA (2011) Combining electrophoresis with detection under ultraviolet light and multiple ultrafiltration for isolation of humic fluorescence fractions. Anal Chim Acta 690:263-268

12. Richard C, Coelho C, Guyot G, Shaloiko L, Trubetskoj O, Trubetskaya O (2011) Fluorescence properties of the $<5 \mathrm{kDa}$ molecular size fractions of a soil humic acid. Geoderma 163:24-29
13. Baglieri A, Vindrola D, Gennari M, Negre M (2014) Chemical and spectroscopic characterization of insoluble and soluble humic acid fractions at different $\mathrm{pH}$ values. Chem Biol Technol Agric 1:1-11

14. Watanabe A, Maie N, Hepburn A, McPhail DB, Abe T, Ikeya K, Ishida Y, Ohtani H (2004) Chemical characterization of Japanese Humic Substances Society standard soil humic and fulvic acids by spectroscopic and degradative analyses. Humic Subs Res 1:18-28

15. Ikeya K, Watanabe A (2003) Direct expression of an index for the degree of humification of humic acids using organic carbon concentration. Soil Sci Plant Nutr 49:47-53

16. Ohno T (2002) Fluorescence inner-filtering correction for determining the humification index of dissolved organic matter. Environ Sci Technol 36:742-746

17. Childers JW, Palmer RA (1986) A comparison of photoacoustic and diffuse reflectance detection in FTIR spectrometry. Am Lab 18:22-38

18. Fery-Forgues S, Lavabre D (1999) Are fluorescence quantum yields so tricky to measure? A demonstration using familiar stationery products. J Chem Educ 76:1260

19. Trubetskoj OA, Trubetskaya OE, Afanas'eva GV, Reznikova Ol, Saiz-Jimenez C (1997) Polyacrylamide gel electrophoresis of soil humic acid fractionated by size-exclusion chromatography and ultrafiltration. J Chromatogr A 767:285-292

20. Kumada K (1987) Chemistry of soil organic matter. Japan Scientific Societies Press-Elsevier, Tokyo

21. Aoyama M (2001) Do humic substances exhibit fluorescence? In: Swift RS, Spark KM (ed) Understanding and managing organic matter in soils, sediments, and waters. International Humic Substances Society, Inc, St Paul, pp 125-131

22. Aoyama M (1999) Chromatographic separation of fluorescent substances from humic acids. In: Davies G, Ghabbour EA (ed) Understanding humic substances: advanced methods. Properties and applications. The Royal Society of Chemistry, Cambridge, pp 179-189

23. Aoyama M, Watanabe A, Nagao S (2000) Characterization of the 'fluorescent fraction' of soil humic acids. In: Ghabbour EA, Davies G (ed) Humic substances: versatile components of plant. Soil and Water. The Royal Society of Chemistry, Cambridge, pp 125-133

24. Alberts JJ, Takács M (2004) Total luminescence spectra of IHSS standard and reference fulvic acids, humic acids and natural organic matter: comparison of aquatic and terrestrial source terms. Org Geochem 35:243-256

25. Coble PG (1996) Characterization of marine and terrestrial DOM in seawater using excitation-emission matrix spectroscopy. Mar Chem 51:325-346

26. Yamashita Y, Tanoue E (2003) Chemical characterization of protein-like fluorophores in DOM in relation to aromatic amino acids. Mar Chem 82:255-271

27. Ding G, Amarasiriwardena D, Herbert S, Novak J, Xing B (2000) Effect of cover crop systems on the characteristics of soil humic substances. In: Ghabbour EA, Davies G (ed) Humic substances: versatile components of plant, soil and water. The Royal Society of Chemistry, Cambridge, pp 53-61

28. D'Orazio V, Senesi N (2009) Spectroscopic properties of humic acids isolated from the rhizosphere and bulk soil compartments and fractionated by sizeexclusion chromatography. Soil Biol Biochem 41:1775-1781

29. Zaccheo P, Cabassi G, Ricca G, Crippa L (2002) Decomposition of organic residues in soil: experimental technique and spectroscopic approach. Org Geochem 33:327-345

30. Boeriu CG, Bravo D, Gosselink RJA, van Dam JEG (2004) Characterisation of structure-dependent functional properties of lignin with infrared spectroscopy. Ind Crops Prod 20:205-218

31. Ferrari E, Francioso O, Nardi S, Saladini M, Ferro ND (2011) DRIFT and HR MAS NMR characterization of humic substances from a soil treated with different organic and mineral fertilizers. J Mol Struc 998:216-224

32. Baes AU, Bloom PR (1989) Diffuse reflectance and transmission Fourier transform infrared (DRIFT) spectroscopy of humic and fulvic acids. Soil Sci Soc Am J 53:695-700 